2020-07

\title{
Particle-water interactions of bismuth under simulated estuarine conditions
}

Knight, LJ

http://hdl.handle.net/10026.1/15559

10.1016/j.chemosphere.2020.126400

Chemosphere

Elsevier BV

All content in PEARL is protected by copyright law. Author manuscripts are made available in accordance with publisher policies. Please cite only the published version using the details provided on the item record or document. In the absence of an open licence (e.g. Creative Commons), permissions for further reuse of content should be sought from the publisher or author. 


\section{Particle-water interactions of bismuth under}

\section{2 simulated estuarine conditions}

4 Lydia J. Knight, Andrew Turner*

$5 \quad{ }^{1}$ School of Geography, Earth and Environmental Sciences, University of Plymouth, Drake 6 Circus, Plymouth PL4 8AA, UK

7

8

$9 \quad *$ aturner@plymouth.ac.uk

10

11 Accepted in Chemosphere 29 ${ }^{\text {th }}$ February 2020

12

doi.org/10.1016/j.chemosphere.2020.126400

13 
Although the production and usage of bismuth $(\mathrm{Bi})$ have been increasing, very little is known about the environmental behaviour of this heavy metal. In the present study, the particle-water interactions of $\mathrm{Bi}$ are examined under controlled conditions in which the metal is added as a tracer to estuarine sediment suspended in different, environmentally-relevant aqueous solutions. Adsorption isotherms were always linear over the Bi concentration range employed (up to $2000 \mu \mathrm{g} \mathrm{L}$ $\left.{ }^{1}\right)$ and sediment-water distribution coefficients derived from isotherm gradients, $K_{\mathrm{D}}\left(\mathrm{L} \mathrm{kg}^{-1}\right)$, displayed an inverse dependence on $\mathrm{pH}$ in river water (and ranging from $K_{\mathrm{D}}=106,000 \mathrm{~L} \mathrm{~kg}^{-1}$ at pH 5.0 to $K_{\mathrm{D}}=$ $17,700 \mathrm{~L} \mathrm{~kg}^{-1}$ at $\mathrm{pH} 9.0$ ) that were consistent with the adsorption of hydroxo-complexes to the sediment surface. Higher adsorption in ultra-pure water of the same $\mathrm{pH}$ as river water and an order of magnitude increase in adsorption in seawater at pH $8.0\left(K_{\mathrm{D}}=1,530,000 \mathrm{~L} \mathrm{~kg}^{-1}\right)$ and $0.7 \mathrm{M} \mathrm{NaNO}_{3}$ at $\mathrm{pH} 6.5\left(K_{\mathrm{D}}=4,290,000 \mathrm{~L} \mathrm{~kg}^{-1}\right)$, however, required the presence of additional species or processes that are likely related to organic complexation of the metal. Thus, experiments conducted in mixtures of river water and seawater in the absence of sediment suggested that Bi may also be bound to colloidal organic molecules that undergo flocculation and salting out on estuarine mixing. Compared with other metals studied under similar conditions, Bi displays a high reactivity towards sediment particles and is, therefore, predicted to be retained in estuaries to a significant extent from catchment sources.

Keywords: bismuth; adsorption; rivers; estuaries; sediment; flocculation

\section{Introduction}

Bismuth is the heaviest element in Group 15 of the Periodic Table whose only naturally occurring isotope $\left({ }^{209} \mathrm{Bi}\right)$ is extremely weakly radioactive and decays with a half-life of about $2 \times 10^{19}$ years (Beeman et al., 2012). Bismuth is widely distributed in the environment with an average crustal abundance of $0.2 \mathrm{ppm}$ (Das et al., 2006) but also occurs in bismite $\left(\mathrm{Bi}_{2} \mathrm{O}_{3}\right)$ and bismuthinite $\left(\mathrm{Bi}_{2} \mathrm{~S}_{3}\right)$ from which it may be obtained as a by-product of copper and lead ores (Ayres and Hellier, 1998). Although $\mathrm{Bi}$ can exist in a number of oxidation states, the trivalent form is the most stable in the environment; this contrasts with the Group 15 metalloids, As and Sb, whose most stable state is the pentavalent (Filella, 2010).

Bismuth has no known biological role and is believed to be the least toxic heavy metal to humans, although some toxicity is exhibited towards certain bacteria and macroalgae (Kearns and Turner, 2016). Its antibacterial properties have been exploited in pharmaceutical products treating bacterial 
infections as well as medications treating ulcers and gastrointestinal disorders (Tremaine, 2000; Kotani et al., 2005). Bismuth and its compounds are also used in cosmetics, paints, fusible alloys, catalysts and semiconductors (Ayres and Hellier, 1998), and recently Bi has gained popularity as a non-toxic replacement for lead in upland and waterfowl hunting shot (Fahay et al., 2008).

Despite these applications and a sharp increase in the recent global production of $\mathrm{Bi}$ to over 13,000 tonnes in 2015 (Kelly and Matos, 2017), there exists very little information on the environmental behaviour of the metal. Filella (2010) suggests that this is due to low concentrations in the environment, often attributed to the insolubility of its compounds, and low toxicity to humans. Her review of concentrations of $\mathrm{Bi}$ in natural waters revealed a wide dispersion of values (but usually $<1$ $\mu \mathrm{L} \mathrm{L}^{-1}$ ), which can be partly accounted for by external contamination during sampling and analysis and by lack of information provided on whether or how samples were filtered. Moreover, an examination of stability constants used in aqueous speciation calculations were found to be indirectly sourced from a limited number of old references, one of which when translated from Russian was found to contain an important error that was subsequently reproduced in the key reference work of Ahrens (1968). Filella (2010) also suggests that no studies of Bi adsorption to heterogeneous solids had been undertaken and that the metal had been overlooked in sorption constant estimations derived from free energy regressions. To our knowledge, the only adsorption experiments conducted with $\mathrm{Bi}$ are reported by Ulrich and Dedueidre (1993). Here, the interactions of ${ }^{210} \mathrm{Bi}$ (as a radiotracer) with montmorillonite clay were examined under varying conditions of $\mathrm{pH}$ and ionic strength. Distribution coefficients derived from adsorbed to aqueous concentration ratios and ranging from $10^{4}$ to $10^{7} \mathrm{~L} \mathrm{~kg}^{-1}$ were later employed by Serne (2007) in order to evaluate the fate, transport and risk of $\mathrm{Bi}$ in agricultural soils and river bank sediments.

Because of the dearth of information on the behaviour of $\mathrm{Bi}$ in the natural environment, the present study set out to systematically examine the adsorption of the metal to estuarine sediment under different conditions of $\mathrm{pH}$, ionic composition and salinity. The study employs protocols that we have adopted before and relies on the addition of the metal as a tracer to aqueous suspensions and at concentrations that are detectable by quadrupole ICP-MS (Turner, 2007; Turner et al., 2010). The sorption constants derived will enable the transport and fate of $\mathrm{Bi}$ to be evaluated and modelled more accurately in rivers and estuaries, and will improve our more general understanding of the behaviour of $\mathrm{Bi}$ in the aquatic environment.

\section{Methods}




\subsection{Sampling}

River water used in the experiments was collected on a weekly basis between May and July 2019 in a 5-L high density polyethylene carboy from the Erme near Ivybridge, southwest England (50.388313, 3.9215163). Here, the bed profile is of low permeability, being comprised of large granite boulders derived from the protected moorland of central southern Dartmoor (a National Park), and average river flow is $1.95 \mathrm{~m}^{3} \mathrm{~s}^{-1}$ (National Flow River Archive, 2017). About $0.5 \mathrm{~kg}$ of surficial, oxic sediment from the protected saltmarshes of the upper Erme estuary (50.332221, -3.9337894) was sampled using a tapered plastic spatula and stored in a zip-locked polyethylene bag. Seawater was available on tap in the laboratory having been previously collected in bulk from the English Channel.

\subsection{Sample processing and characterisation}

River water and seawater were vacuum-filtered through $0.45 \mu \mathrm{m}$ cellulose acetate filters into a series of acid-cleaned 1-L polyethylene bottles and used within 24 hours. Estuarine sediment was sieved through a $63 \mu \mathrm{m}$ nylon mesh with the aid of filtered river water and transferred to a series of $50 \mathrm{~mL}$ Fisherbrand screw-capped polypropylene centrifuge tubes. The contents of each tube were centrifuged for 20 minutes at $3500 \mathrm{rpm}$ before supernatants were poured off and remaining sediment frozen until required.

The $\mathrm{pH}$ and conductivity (hence salinity) of aqueous samples were determined using colour-fixed indicator sticks or a Jenway 3305 probe and a YSI 85 conductivity meter, respectively. The presence of Bi was checked by inductively coupled plasma-mass spectrometry (ICP-MS; see below) after $10 \mathrm{~mL}$ of filtered river water had been spiked with $100 \mu \mathrm{L}$ of concentrated $\mathrm{HCl}$ (VWR ARISTAR) and $2 \mathrm{ml}$ of filtered seawater had been diluted to $10 \mathrm{~mL}$ with $1 \mathrm{M} \mathrm{HCl}$. A subsample of fractionated sediment was thawed out and homogenised using a plastic spatula before $\sim 1 \mathrm{~g}$ aliquots were used to determine moisture content on drying at $105^{\circ} \mathrm{C}$ for 24 hours, loss on ignition after combustion at $550^{\circ} \mathrm{C}$ for 4 hours, and mean particle diameter using a Malvern Instruments Hydro 2000G Mastersizer. In triplicate, $0.5 \mathrm{~g}$ of dried sediment and $0.25 \mathrm{~g}$ of a certified reference sample (SS-2 Contaminated Soil, 140-025-002) were digested in $10 \mathrm{~mL}$ of boiling aqua regia (VWR ARISTAR $\mathrm{HCl}$ and $\mathrm{HNO}_{3}$ ) in $50 \mathrm{~mL}$ Pyrex beakers covered with watch glasses; controls were performed likewise but in the absence of solids. The cooled digests were filtered through Whatman $85 \mathrm{~g} \mathrm{~m}^{-2}$ acid-resistant circles and diluted to $50 \mathrm{~mL}$ with Millipore Milli-Q water (MQW). Concentrations of $\mathrm{Bi}$ and a suite of other elements were determined in the diluted digests by ICP-MS (see below). 
111 The general approach for the adsorption isotherm experiments was adapted from Turner et al.

112 (2010) as follows. A $100 \mathrm{mg} \mathrm{L}^{-1}$ working solution of Bi was prepared in a $50 \mathrm{~mL}$ volumetric flask by 113 diluting $500 \mu \mathrm{L}$ of $10,000 \mathrm{mg} \mathrm{L}^{-1} \mathrm{Bi}$ standard (VWR ARISTAR) in filtered river water. Meanwhile, a 114 slurry stock of $\sim 4 \mathrm{~g}$ dry sediment $\mathrm{L}^{-1}$ was prepared by adding $0.5 \pm 0.05 \mathrm{~g}$ of thawed sediment to 50 $115 \mathrm{~mL}$ of filtered river water in a volumetric flask. To a series of screw-capped $50 \mathrm{~mL}$ polypropylene 116 centrifuge tubes, $1 \mathrm{~mL}$ of slurry stock was diluted in $40 \mathrm{~mL}$ of river or sea water to give a particulate 117 concentration on a dry weight basis of $\sim 100 \mathrm{mg} \mathrm{L}^{-1}$. Bismuth was pipetted to the centrifuge tubes 118 from the working standard to produce a concentration series ranging from 10 to $2000 \mu \mathrm{g} \mathrm{L}^{-1}$, with 119 two concentrations in each isotherm performed in triplicate. The centrifuge tubes were 120 subsequently agitated at room temperature $\left(\sim 20^{\circ} \mathrm{C}\right)$ and in the dark in the horizontal position on a 121 lateral shaker for $16-18 \mathrm{~h}$ at $100 \mathrm{rpm}$. Following incubation, particulate and aqueous phases were separated by vacuum-filtration through $0.45 \mu \mathrm{m}$ cellulose acetate membranes. Ten $\mathrm{mL}$ filtrate aliquots were transferred to $30 \mathrm{~mL}$ Thermo Scientific polystyrene Sterilin tubes and acidified with $100 \mu$ l of concentrated $\mathrm{HCl}$. Filters were transferred to Sterilin tubes and Bi was extracted for $18 \mathrm{~h}$ in $10 \mathrm{~mL}$ of $1 \mathrm{M} \mathrm{HCl}$ and $10 \mathrm{~mL}$ of $1 \mathrm{M} \mathrm{HNO}_{3}$.

This process was repeated using MQW in place of river water, and after adjusting (and, if necessary, maintaining) the $\mathrm{pH}$ of river water to 5 and 9 by dropwise addition of $1 \mathrm{M} \mathrm{HNO}_{3}$ and $1 \mathrm{M} \mathrm{NaOH}$, respectively. Experiments were also repeated in seawater and using solutions of $0.7 \mathrm{M} \mathrm{NaCl}$ (Fisher Scientific Extra Pure) and $0.7 \mathrm{M} \mathrm{NaNO}_{3}$ (VWR AnalaR) but with $4 \mathrm{~mL}$ filtrates diluted to $20 \mathrm{~mL}$ in $1 \mathrm{M}$ $\mathrm{HCl}$. Bismuth adsorption was also studied at a single concentration $\left(1000 \mu \mathrm{g} \mathrm{L}^{-1}\right)$ across the estuarine gradient in $50 \mathrm{~mL}$ solutions of salinities $0,2,5,10,15,20$ and 30 created by mixing filtered river water and filtered seawater end-members in different proportions. This process was also repeated in the absence of sediment in order to evaluate the extent of flocculation and filter adsorption of the metal. To assess the significance of container adsorption, the emptied centrifuge tubes arising from various experiments and different added $\mathrm{Bi}$ concentrations were extracted with $25 \mathrm{~mL}$ of $20 \% \mathrm{HNO}_{3}$ for $16-18 \mathrm{~h}$ under lateral agitation at $100 \mathrm{rpm}$.

\subsection{ICP-MS analysis}

Acidified and diluted filtrates, filter extracts, centrifuge tube extracts, and sediment digests and controls (and any dilutions thereof) were analysed in triplicate for $\mathrm{Bi}$ (and, for sediment digests, $\mathrm{Al}$, 140 As, Ca, Fe, Mn and Sb) by ICP-MS using a Thermo Scientific iCAP TQ with a concentric glass nebuliser and cyclone spray chamber. The instrument was calibrated using blanks and standards of 1,4,10, 
standardisation was achieved by addition of $20 \mu \mathrm{g} \mathrm{L}^{-1}$ of Ir to all samples and standards. Instrument drift was monitored with standard checks after every ten samples, with reanalysis performed if deviation of more than $10 \%$ from the expected value occurred. Elemental concentrations returned for the certified reference soil were within stated tolerance intervals with the exception of $\mathrm{Bi}$ (no natural geosolid appears to be certified with respect to this metal). Under conditions where Bi adsorption was replicated $(n=3)$, precision, as relative standard deviation, ranged from 5.1 to $28.2 \%$ (median $=12.6 \%$ ) for the aqueous phase and 2.3 to $46.4 \%$ (median $12.5 \%$ ) for filter extracts.

\section{Results}

\subsection{Sample characteristics}

The $\mathrm{pH}$ of filtered Erme river water used in the experiments ranged from 6.2 to 6.5 , while conductivity varied from 63.5 to $107 \mu \mathrm{S} \mathrm{cm}^{-1}$, and the $\mathrm{pH}$ and salinity of filtered English Channel seawater were 8.0 and 30.8, respectively. Although dissolved organic matter was not determined in the aqueous samples, previous measurements of dissolved organic carbon performed in adjacent rivers draining the same region of Dartmoor and in the local coastal region of the English Channel indicate typical values of about 1.7 and $1.4 \mathrm{mg} \mathrm{L}^{-1}$, respectively (Rawling et al., 1998). The mean, background concentration of $\mathrm{Bi}$ in river water was $0.28 \pm 0.01 \mu \mathrm{g} \mathrm{L}^{-1}$ but in seawater the metal was below the detection limit of $<0.05 \mu \mathrm{g} \mathrm{L}^{-1}$.

The fractionated estuarine sediment use in the experiments had a median particle size of $19.3 \mu \mathrm{m}$ and a moisture content of $59.9 \%$, with a combustible mass when dry (i.e. organic content) of $13.3 \%$. Dry weight concentrations of $\mathrm{Al}, \mathrm{Ca}, \mathrm{Fe}$ and $\mathrm{Mn}$ (in $\mu \mathrm{g} \mathrm{g}^{-1}$ and as the mean \pm one standard deviation of three determinations) were $17,500 \pm 185,2670 \pm 9.1,41,700 \pm 97.1$ and $332 \pm 2.54$, respectively, while concentrations of $\mathrm{Bi}$ and the other group VA elements, As and $\mathrm{Sb}$, were $0.23 \pm 0.09,2.49 \pm 0.86$ and $3.12 \pm 0.35$, respectively.

\subsection{Container adsorption}

Although the aims of the study were to define the adsorption characteristics of $\mathrm{Bi}$ to estuarine sediment, it is useful, more generally, to understand how the metal behaves under controlled and contained laboratory conditions, and in particular whether there is any loss to non-environmental phases such as the reactor vessel or filter membrane. Mass balance considerations from the isotherm experiments revealed average percentages of added Bi that could not be accounted for in the sediment and aqueous phases ranging from about 26 to 64 (Table 1) but there was no clear relationship with the $\mathrm{pH}$ or ionic strength of the solution or the quantity of $\mathrm{Bi}$ added. Subsequent acid-washing of selected emptied centrifuge tubes revealed that the majority of Bi lost had 
undergone heterogeneous adsorption to container surfaces, with analysis of filters arising from experiments conducted in the absence of sediment revealing additional loss of the metal to the membranes but not quantitatively attaining complete mass balance. Thus, it is critical to measure the distribution of $\mathrm{Bi}$ in all environmental phases considered in laboratory experiments as estimates relying on difference would lead to significant errors in constants defining adsorption processes.

\subsection{Adsorption isotherms}

181

Isotherms for $\mathrm{Bi}$ adsorption to fractionated estuarine sediment are shown for $\mathrm{MQW}$ at $\mathrm{pH} 6.5$ and river water over a range of $\mathrm{pH}$ values in Figure 1. Here, concentrations of Bi extracted from sediment and normalised to dry mass, $[\mathrm{Bi}]_{\mathrm{ads}}$, are shown as a function of Bi concentrations measured in the aqueous phase, $[\mathrm{Bi}]_{\mathrm{aq}}$, after a $16-18 \mathrm{~h}$ incubation period. Note that in MQW, the full data set is not shown as the higher concentrations of added Bi were accompanied by significant shifts in aqueous $\mathrm{pH}$. Isotherms were best defined by a linear model in all cases, with slopes of the relationships used to derive the sediment-water distribution coefficients, $K_{\mathrm{D}}\left(\right.$ in $\mathrm{L} \mathrm{kg}^{-1}$ ):

$K_{\mathrm{D}}=[\mathrm{Bi}]_{\mathrm{ads}} * 10^{3} /[\mathrm{Bi}]_{\mathrm{aq}}$

shown in Table 2. Adsorption of $\mathrm{Bi}$ increases with a reduction in $\mathrm{pH}$ and from a $K_{\mathrm{D}}$ of $17,700 \mathrm{~L} \mathrm{~kg}^{-1}$ at $\mathrm{pH} 9.0$ to a $K_{\mathrm{D}}$ of $106,000 \mathrm{~L} \mathrm{~kg}^{-1}$ at pH 5.0, but amongst all freshwater media is greatest in MQW $\left(K_{\mathrm{D}}=\right.$ $113,000 \mathrm{~L} \mathrm{~kg}^{-1}$ ) in which contaminant ions and organic matter are absent.

Adsorption isotherms are shown for seawater at $\mathrm{pH} 8.0$ and for aqueous solutions of $\mathrm{NaCl}$ and $\mathrm{NaNO}_{3}$ of equivalent ionic strength (but lower $\mathrm{pH}$ ) in Figure 2. Note here that aqueous concentrations, but not particulate concentrations, are considerably lower than those measured in freshwater above (despite no clear differences in Bi recovery amongst different media reported in Table 1). Consequently, isotherm slopes and values of $K_{\mathrm{D}}$ (shown in Table 2 ) are at least an order of magnitude higher than those derived in river water and MQW.

\subsection{Particle-water interactions along the estuarine gradient}

Values of $K_{\mathrm{D}}$, derived from concentration ratios of $\mathrm{Bi}$ extracted from sediment to $\mathrm{Bi}$ measured in the aqueous phase and for an added $\mathrm{Bi}$ concentration of $1000 \mathrm{~g} \mathrm{~L}^{-1}$, are shown after logarithmic conversion as a function of salinity in Figure 3 . Here, the $x$-axis represents the estuarine gradient, or the extent of mixing of river water and seawater end members. The logged $K_{D}$ data exhibit a significant and positive linear relationship with salinity defined by a slope of 0.0615 and an intercept of about 4. In Figure 4, the percentage of $\mathrm{Bi}$ added at a concentration of $1000 \mu \mathrm{g} \mathrm{L}^{-1}$ that is retained by filtration but in the absence of estuarine sediment is shown along the estuarine gradient.

Percentages are lowest at the end-members where they may be attributed to filter adsorption and, 
possibly, precipitation, and are enhanced by end-member mixing, with values exceeding $70 \%$ in the mid-estuarine region.

\section{Discussion}

The findings of the present work indicate substantive loss of Bi to container surfaces, an effect that has been reported for glass and plastic in previous analytical and experimental studies of the metal in freshwater and seawater (Lee, 1982; Ulrich and Deguelde, 1993). Clearly, studies involving Bi as a tracer under contained experimental conditions require careful consideration of reactor adsorption and the direct analysis of all environmental phases involved. With respect to adsorption studies, it is critical that both particulate and aqueous $\mathrm{Bi}$ are measured and that derivation of concentrations does not rely on difference. Isotherms reported here and determined directly define the adsorption of $\mathrm{Bi}$ to fractionated estuarine sediment suspended in various environmentally relevant solutions and appear to be the first documented for this metal using a natural sorbent. That isotherms are linear suggests binding sites at the particle surface are not limited for $\mathrm{Bi}$, at least over the concentration range studied, and adsorption constants derived are likely to be applicable at lower, more environmentally realistic concentrations of the metal.

Increasing adsorption of $\mathrm{Bi}\left(\mathrm{as} K_{\mathrm{D}}\right.$ ) with decreasing $\mathrm{pH}$ and increasing salinity are not consistent with the adsorption of metal cations to soils or sediment. Here, adsorption is predicted to increase with $\mathrm{pH}$ as binding sites become progressively deprotonated and to decrease with increasing salinity because of competitive adsorption with seawater cations and complexation seawater anions (Peng et al., 2003; Zwolsman et al., 1997). For Bi, therefore, additional or alternative adsorbing species appear to be significant in sediment-water suspensions under the conditions tested.

Unfortunately, the aqueous speciation of $\mathrm{Bi}$ is poorly understood, and relevant constants appear to have been taken, often indirectly or inappropriately, from old sources (Filella, 2010). What is known is that $\mathrm{Bi}^{3+}$ is stable under only strongly acidic conditions and with increasing $\mathrm{pH}$ there is an increase in the variety and abundance of hydroxo-complexes. Under near-neutral freshwater conditions similar to those adopted herein, calculations undertaken by Ulrich and Deguelde (1993) indicate that 99.9\% of the metal should exist as $\mathrm{Bi}(\mathrm{OH})_{3}$, with the remainder comprised of $\mathrm{Bi}(\mathrm{OH})^{2+}$ and a vanishingly small quantity of free $\mathrm{Bi}^{3+}$. The authors suggest that adsorption can be modelled as a series of quasi-irreversible complexation reactions that, with respect to the sediment surface, $=\mathrm{X}$, can be written as follows:

$=\mathrm{X}-\mathrm{O}-\mathrm{H}+\mathrm{Bi}(\mathrm{OH})_{3} \longrightarrow=\mathrm{X}-\mathrm{O}-\mathrm{Bi}(\mathrm{OH})_{2}+\mathrm{H}_{2} \mathrm{O}$ 
241 Presumably, the dependence of $\mathrm{Bi}$ adsorption on $\mathrm{pH}$ arises from shifts in the aqueous speciation of

242 the metal and differences in the complexation constants of each reaction. Specifically, higher 243 adsorption at $\mathrm{pH} 5$ may be attributed to the greater relative abundance of $\mathrm{Bi}^{3+}$ and a relatively high complexation constant for reaction 3, while lower adsorption at pH 9 may be attributed to the greater relative abundance of $\mathrm{Bi}(\mathrm{OH})_{3}$ and a relatively low complexation constant for reaction 1 . The neutral hydroxide is also likely to be subject to non-specific sorption to the hydrophobic container surfaces and may explain the loss of Bi observed in the experiments.

In seawater, the same species, plus $\mathrm{Bi}(\mathrm{OH})_{4}^{-}$, have been proposed (Byrne, 2002). Because of the higher $\mathrm{pH}$ of seawater than MQW or river water, a reduction in adsorption with increasing salinity would be predicted on the basis of the arguments above. However, an exponential increase in $K_{\mathrm{D}}$ across the estuarine gradient (Figure 3 ) requires that additional species or processes are present. It has been suggested that cationic chloro-complexes or oxychloro-complexes of high reactivity occur in seawater (Bertine et al., 1996; Kabata-Pendias and Mukherjee, 2007) but similar adsorption of Bi observed in solutions of $\mathrm{NaCl}$ and $\mathrm{NaNO}_{3}$ shown in Figure 2 imply that the distribution of $K_{\mathrm{D}}$ across the estuarine gradient may be related to ionic strength. Significantly, we note a doubling in adsorption (as $K_{\mathrm{D}}$ ) of $\mathrm{Bi}$ to montmorillonite from ionic strengths of $0.01 \mathrm{M}$ to $0.2 \mathrm{M}$ reported in Ulrich and Degueldre (1993) although no explanation is proposed by the authors.

Although $\mathrm{Bi}$ is known to bind with functional groups on the surfaces of macroalgae (Kearns and Turner, 2016), no information exists in the literature on the complexation of Bi by dissolved organic ligands in the environment. The results presented here, however, suggest that the metal is able to interact with dissolved organic matter in different ways. Thus, firstly, higher adsorption in MQW than in river water at the same $\mathrm{pH}$ (Table 1) suggests that natural organic ligands compete with adsorption sites on the sediment surface for aqueous $\mathrm{Bi}$ and act to stabilise a fraction of the metal in solution. Secondly, the capture of significant quantities of Bi on filters arising from the mixing of endmembers in the absence of sediment (Figure 4) suggests that associations of Bi with macromolecular organic matter in river water are destabilised by the addition of seawater ions and are subject to

267 flocculation or coagulation (Zwolsman et al., 1997; Windom et al., 1999). Thirdly, the exponential

268 increase in $K_{D}$ with increasing salinity is consistent with a modified version of the Setschenow

269 equation and suggests that organic complexes of Bi may be subject to salting out through

270 electrostriction (Turner et al., 2001). 
Despite uncertainties in the aqueous speciation of $\mathrm{Bi}$ and the mechanisms by which it interacts at the particle surface, it is clear that the metal has a high affinity for sediment compared with other metals. Figure 5 compares $K_{\mathrm{D}}$ values for Bi derived here with those for a variety of metals studied as tracers (including radiotracers) in suspensions of estuarine sediment from the Plym (adjacent to the Erme) in Plym river water and English Channel seawater undertaken under otherwise identical conditions. Thus, in river water $K_{\mathrm{D}}$ is greatest for $\mathrm{Bi}$ but similar in magnitude to values for $\mathrm{Cd}, \mathrm{Hg}$ and $\mathrm{Zn}$, while in seawater $K_{\mathrm{D}}$ is greatest for $\mathrm{Bi}$ among the metals by almost an order of magnitude. Bismuth is, therefore, highly particle active and estuaries are predicted to be important sinks for river borne sources of the metal. These assertions are consistent with an oceanic input of the metal that is believed to be dominated by an aoelian, and probably volcanic, pathway (Lee et al., 1985/1986), and an estimated oceanic residence time of only 20 years (Bertine et al., 1996).

\section{Conclusions}

Very limited thermodynamic or empirical information exists relating to the behaviour of $\mathrm{Bi}$ in the aquatic environment. Here, it has been shown that $\mathrm{Bi}$, added as a tracer, has a high affinity for sediment suspended in natural and synthetic media, with sediment water distribution coefficients of about 70,000 $\mathrm{L} \mathrm{kg}^{-1}$ in river water at $\mathrm{pH} 6.5$ (and that display an inverse dependency on $\mathrm{pH}$ between 5.0 and 9.0) and 1,500,000 L kg-1 in sea water. Adsorption is attributed to the complexation of various species (believed to be mainly hydroxides) at the particle surface. Results also indicate that a significant fraction of added Bi undergoes flocculation when the salinity of river water is increased, suggesting that Bi has some affinity for organic molecules that are destabilised as the concentration of aqueous ions is increased. With an increase in the global production and usage of Bi, further studies that better define its aqueous speciation and environmental fate are called for.

\section{Declaration of competing interest}

The authors declare that they have no known competing financial interests or personal relationships that could have influenced the findings of the study.

\section{Acknowledgements}

Alex Taylor and Rob Clough (UoP) are acknowledged for technical support throughout. The study was partly funded by a Plymouth Marine Institute HEIF Grant. 
Ahrens, L.H., 1968. Bismuth. In: Handbook of Geochemistry, Volume II-5, ed. K.H. Wedepohl, Springer, Berlin.

Ayres, D.C., Hellier, D.G., 1998. Dictionary of Environmentally Important Chemicals. Blackie Academic and Professional, London, 332pp.

Beeman, J.W., Biassoni, M., Brofferio, C., Bucci, C., Capelli, S., Cardani, L., Carrettoni, M., Clemenza, M. and others, 2012. First measurements of the partial widths of $\mathrm{Bi}-209$ decay to the ground and to the first excited states. Physical Review Letters, 108 no. 062501 DOI:

Bertine, K.K., Koide, M., Goldberg, E.D., 1996. Comparative marine chemistries of some trivalent metals - bismuth, rhodium and rare earth elements. Marine Chemistry 53, 89-100.

Byrne, R., 2002. Inorganic speciation of dissolved elements in seawater: the influence of metals speciation in water. Marine Chemistry, 25, $163-181$.

Das, A.K., Chakraborty, R., Cervera, M.L., de la Guardia, M., 2006. Analytical techniques for the determination of bismuth in solid environmental samples. Trends in Analytical Chemistry 25, 599608.

Fahey, N.S.C., Karagatzides, J.D., Jayasinghe, R., Tsuji, L.J.S., 2008. Wetland soil and vegetation bismuth content following experimental deposition of bismuth pellets. Journal of Environmental Monitoring 10, 951-954.

Filella, M., 2010. How Reliable Are Environmental Data on 'Orphan' Elements? The Case of Bismuth Concentrations in Surface Waters. Journal of Environmental Monitoring 12, 90-109.

Kabata-Pendias, A., Mukherjee, A., 2007. Trace Elements from Soil to Humans, 1st ed. Springer Science and Business Media, Berlin. Coastal Environment using Three Species of Macroalgae. Environmental Pollution. 208, 435-441. Commodities in the United States. [Online]. Available at: https://www.usgs.gov/centers/nmic/historical-statistics-mineral-and-material-commodities-unitedstates [Accessed August 2019]. 
Kotani, T., Nagai, D., Asahi, K., Suzuki, H., Yamao, F., Kataoka, N., Yagura, T., 2005. Antibacterial properties of some cyclic organobismuth(III) compounds. Antimicrobial agents and chemotherapy 49, 2729-2734.

Lee, D.S., 1982. Determination of bismuth in environmental samples by flameless atomic absorption spectrometry with hydride generation. Analytical Chemistry 54, 1682 - 1686.

Lee, D.S., Edmond, J.M., Bruland, K.W., 1985/1986. Bismuth in the Atlantic and North Pacific: a natural analogue to plutonium and lead. Earth and Planetary Science Letters 76, 254-262.

National River Flow Archive. (2017). Erme at Ermington. [Online]. Available at: https://nrfa.ceh.ac.uk/data/station/meanflow/46006 [Accessed July 2019].

Peng, S.H., Wang, W.X., Chen, J.S., 2003. Partitioning of trace metals in suspended sediments from Huanghe and Chiangjang Rivers in eastern China. Water, Air and Soil Pollution 148, 243-258.

Rawling, M.C., Turner, A., Tyler, A.O., 1998. Particle-water interactions of 2,2',5,5'tetrachlorobiphenyl under simulated estuarine conditions. Marine Chemistry 61, 115-126.

Serne, R.J., 2007. $K_{d}$ Values for Agricultural and Surface Soils for Use in Hanford Site Farm, Residential, and River Shoreline Scenarios. Technical Report for Groundwater Protection Project Characterization of Systems Task. Pacific Northwest National Laboratory, US Department of Energy, Springfield, VA. 87pp.

Tremaine, W.J., 2000. Collagenous colitis and lymphocytic colitis. Journal of Clinical Gastroenterology $30,245-249$.

Turner, A., 2007. Particle-water interactions of platinum group elements under estuarine conditions. Marine Chemistry 103, 103-111.

Turner, A., Millward, G.E., Le Roux, S.M., 2001. Sediment-water partitioning of inorganic mercury in estuaries. Environmental Science and Technology 35, 4648-4654.

Turner, A., Cabon, A., Glegg, G., Fisher, A., 2010. Sediment-water interactions of thallium under simulated estuarine conditions. Geochimica et Cosmochimica Acta 74, 6779-6787.

Ulrich, H.J., Degueldre, C., 1993. The sorption of ${ }^{210} \mathrm{~Pb},{ }^{210} \mathrm{Bi}$ and ${ }^{210} \mathrm{Po}$ on montmorillonite: A study with emphasis on reversibility aspects and on the effect of the radioactive decay of adsorbed nuclides. Radiochimica Acta 62, 81-90.

Windom, H.L., Niencheski, L.F., Smith, R.G., 1999. Biogeochemistry of nutrients and trace metals in the estuarine region of the Patos Lagoon (Brazil). Estuarine, Coastal and Shelf Science 48, 113-123. 

metals (cadmium, copper, zinc) in the Scheldt estuary, southwestern Netherlands: Impact of seasonal variability. Geochimica et Cosmochimica Acta 61, 1635-1652. Table 1: Percentage of added $\mathrm{Bi}$ (as mean \pm one standard deviation) that was unaccounted for in the isotherm experiments conducted in suspensions of fractionated estuarine sediment suspended in different aqueous solutions.

\begin{tabular}{lcc}
\hline aqueous solution & $\mathrm{pH}$ & \% unaccounted \\
\hline MQW & 6.5 & $35.2 \pm 10.7$ \\
river water & 6.5 & $48.0 \pm 9.0$ \\
& 9.0 & $39.6 \pm 15.0$ \\
& 5.0 & $26.2 \pm 7.7$ \\
seawater & 8.0 & $33.9 \pm 9.7$ \\
$0.7 \mathrm{M} \mathrm{NaNO}_{3}$ & 6.5 & $52.8 \pm 8.8$ \\
$0.7 \mathrm{M} \mathrm{NaCl}$ & 6.5 & $63.5 \pm 11.8$ \\
\hline
\end{tabular}

Table 2: Sediment-water distribution coefficients defining the slopes of the isotherms in Figures 1 and 2 along with goodness of fits to the data (note that $p<0.01$ in all cases).

\begin{tabular}{|c|c|c|c|}
\hline aqueous solution & $\mathrm{pH}$ & $K_{\mathrm{D}}, \mathrm{L} \mathrm{kg}^{-1}$ & $r^{2}$ \\
\hline MQW & 6.5 & 113,000 & 0.992 \\
\hline \multirow[t]{3}{*}{ river water } & 6.5 & 68,100 & 0.968 \\
\hline & 9.0 & 17,700 & 0.974 \\
\hline & 5.0 & 106,000 & 0.907 \\
\hline seawater & 8.0 & $1,530,000$ & 0.872 \\
\hline $0.7 \mathrm{M} \mathrm{NaNO}_{3}$ & 6.5 & $4,290,000$ & 0.995 \\
\hline $0.7 \mathrm{M} \mathrm{NaCl}$ & 6.5 & $3,170,000$ & 0.994 \\
\hline
\end{tabular}

373 
Figure 1: Isotherms for $\mathrm{Bi}$ adsorption to fractionated sediment suspended in different freshwater solutions. Solid lines denote best fits by linear regression analysis whose slopes (as $K_{\mathrm{D}}$ ) and goodness of fits are shown in Table 2.

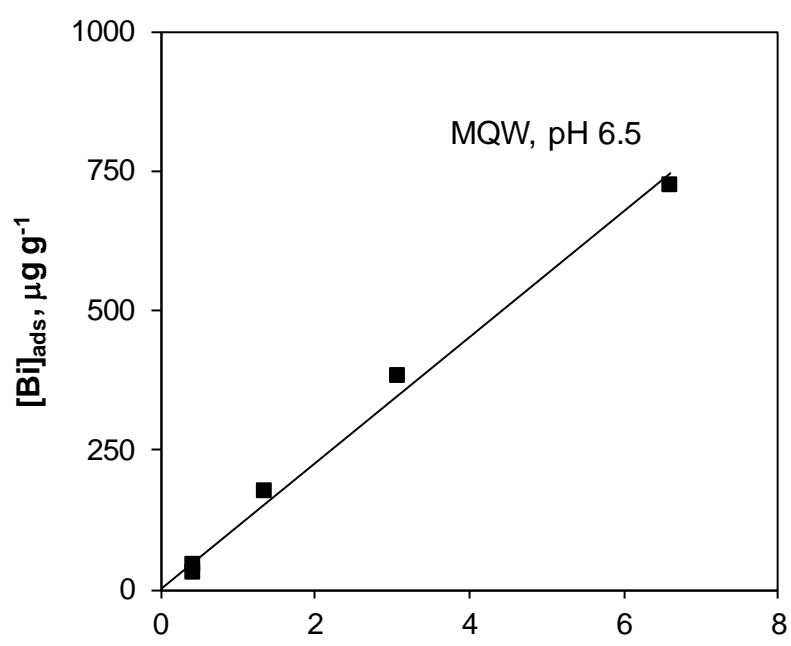

$[\mathrm{Bi}]_{\text {aq }}, \mu \mathrm{g} \mathrm{L}^{-1}$

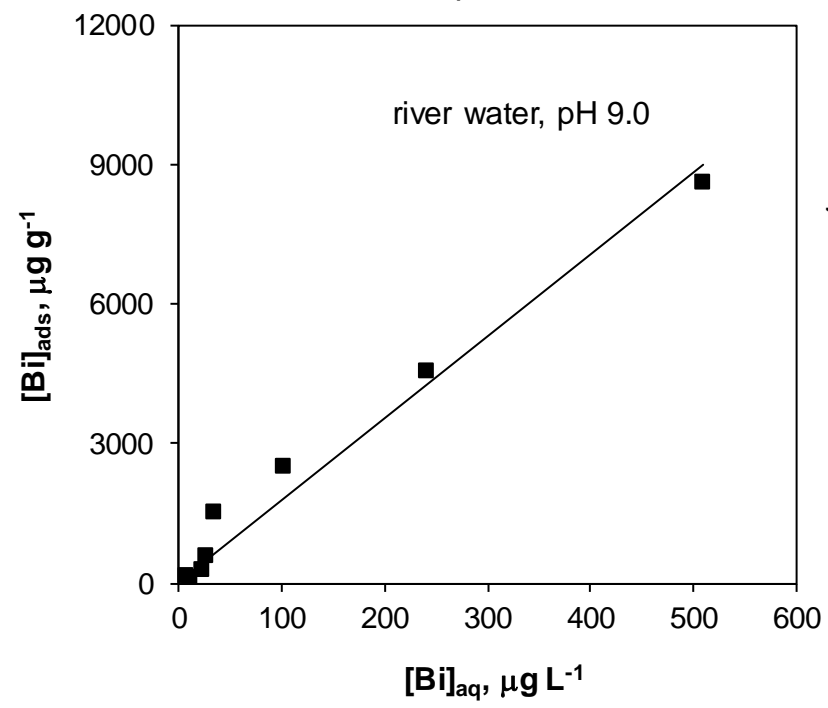

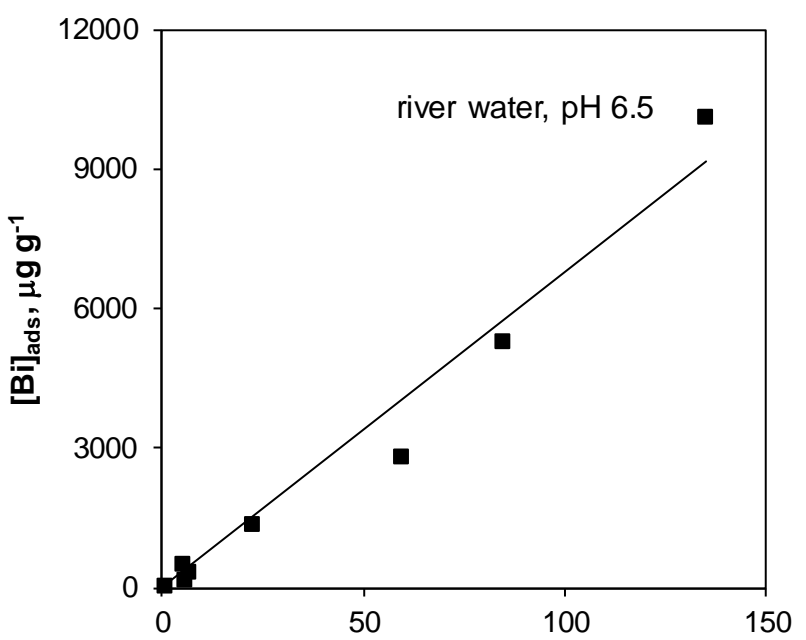

$[\mathrm{Bi}]_{\text {aq }}, \mu \mathrm{g} \mathrm{L}^{-1}$

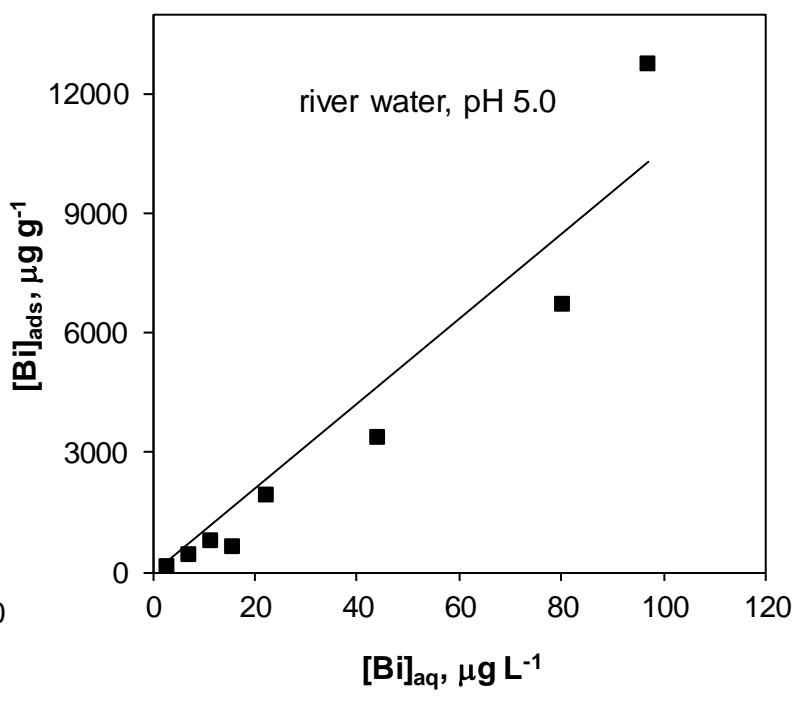


Figure 2: Isotherms for $\mathrm{Bi}$ adsorption to fractionated sediment suspended in different saline media.

Solid lines denote best fits by linear regression analysis whose slopes (as $K_{\mathrm{D}}$ ) and goodness of fits are shown in Table 2.

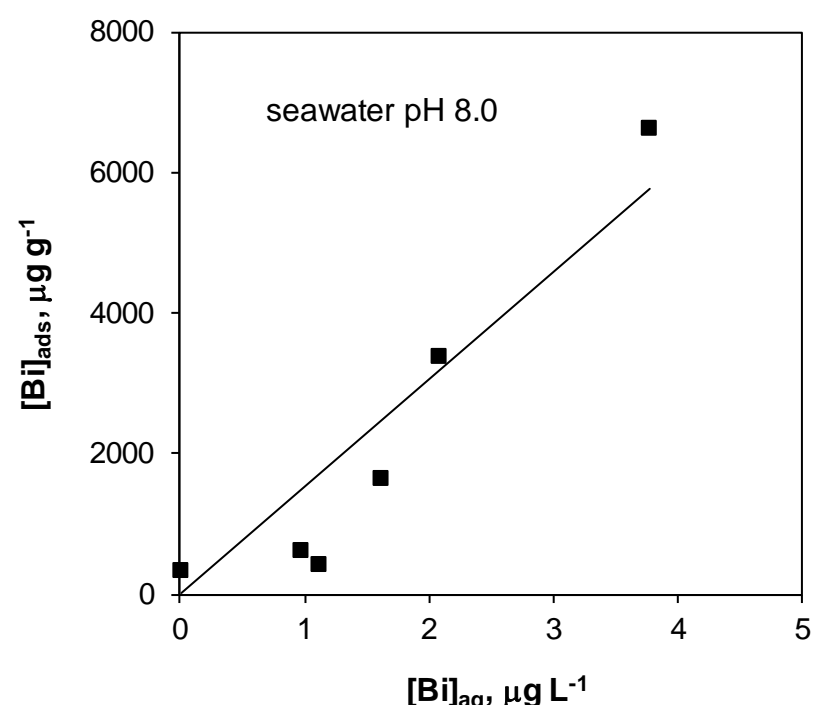

$[\mathrm{Bi}]_{\mathrm{aq}}, \mu \mathrm{g} \mathrm{L}^{-1}$

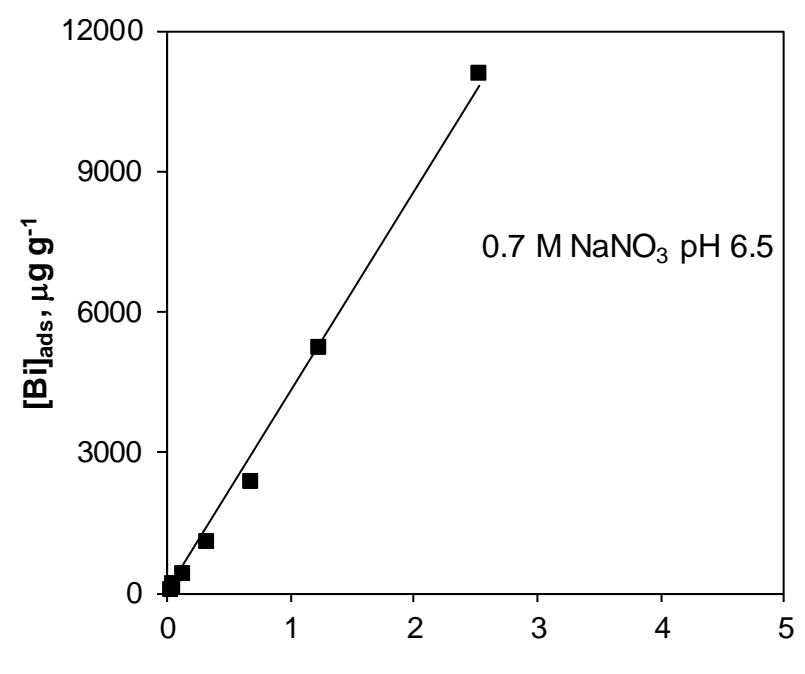

$[\mathrm{Bi}]_{\mathrm{aq}}, \mu \mathrm{g} \mathrm{L}^{-1}$

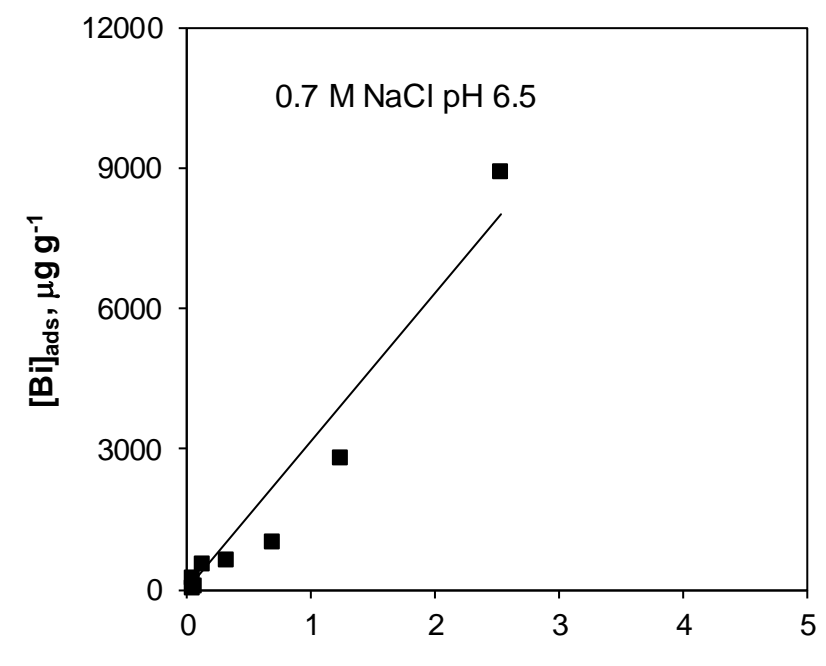

$[\mathrm{Bi}]_{\text {aq }}, \mu \mathrm{g} \mathrm{L}^{-1}$ 
384

385

386

387

388

389

390

391

392

393

394

395

396

397

398

399

400

401

402

403

404

405

406

407

408

409

Figure 3: Logged sediment-water distribution coefficients for Bi (added at a concentration of $1000 \mu \mathrm{g}$ $\left.\mathrm{L}^{-1}\right)$ on mixing river water $(\mathrm{pH} \mathrm{6.3)}$ and seawater $(\mathrm{pH} 8.0)$ and shown as a function of salinity. The solid line denotes the best fit through the data with the equation, goodness of fit and significance annotated.

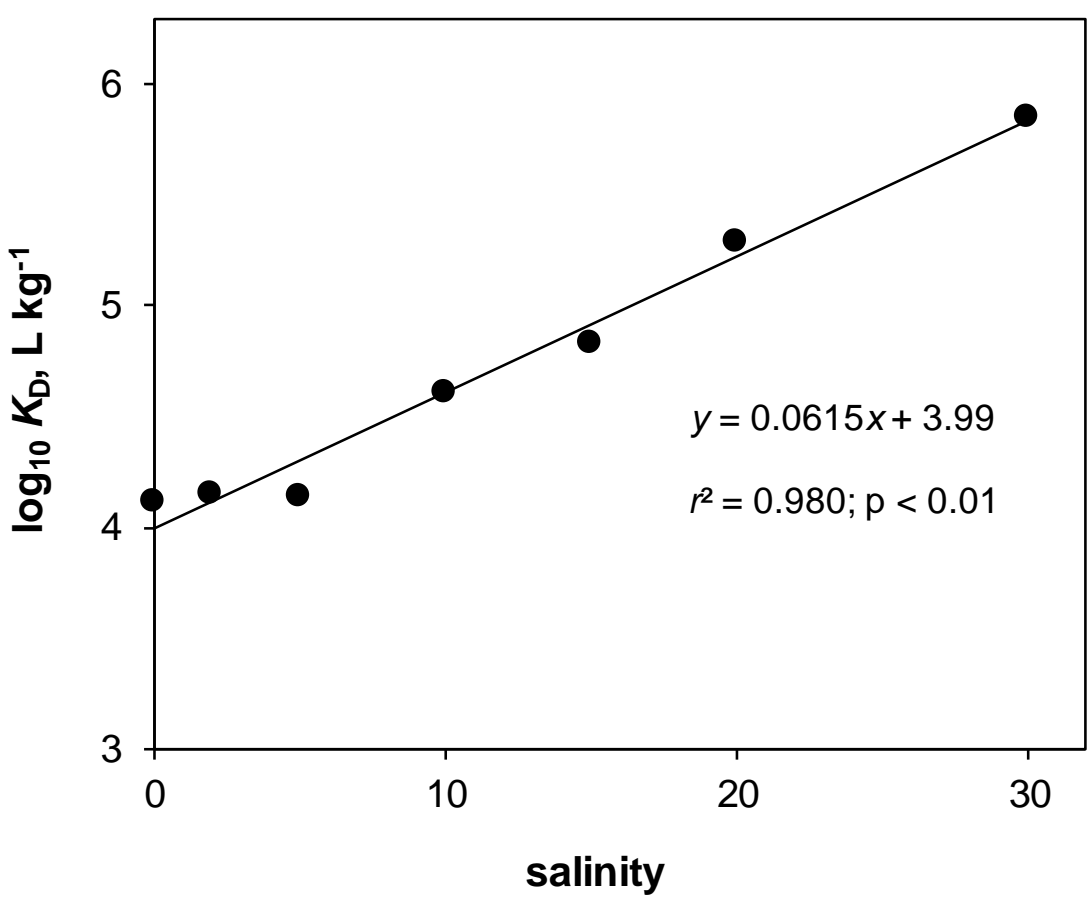

Figure 4: The percentage of $\mathrm{Bi}$ (added at a concentration of $1000 \mu \mathrm{g} \mathrm{L}^{-1}$ ) retained on filters on mixing river water ( $\mathrm{pH}$ 6.3) and seawater ( $\mathrm{pH} 8.0$ ) in the absence of estuarine sediment and shown as a function of salinity.

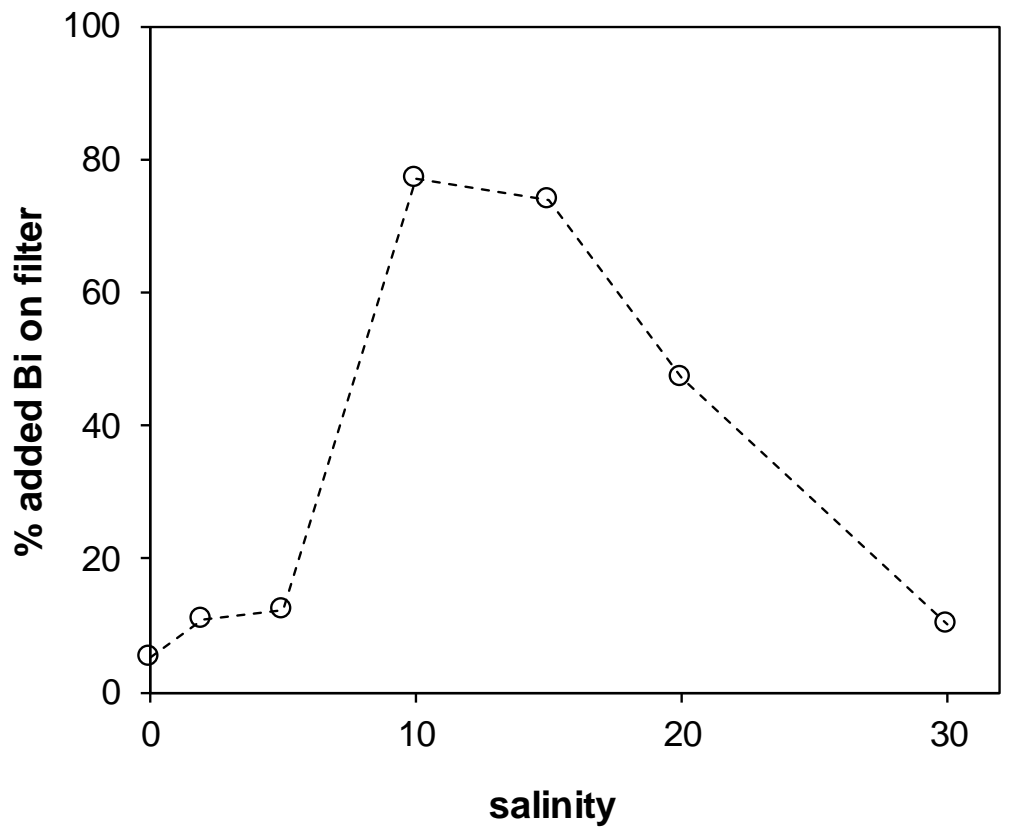


410

411

412

413

414

415

416

417
Figure 5: Logged sediment-water distribution coefficients shown in ascending order for different metals studied as tracers in (a) the River Plym (pH 6 to 7) or River Erme (Bi only) and (b) English Channel seawater $(\mathrm{pH} \sim 8)$. Data are taken from Table 2 and Turner (2007) and references therein.
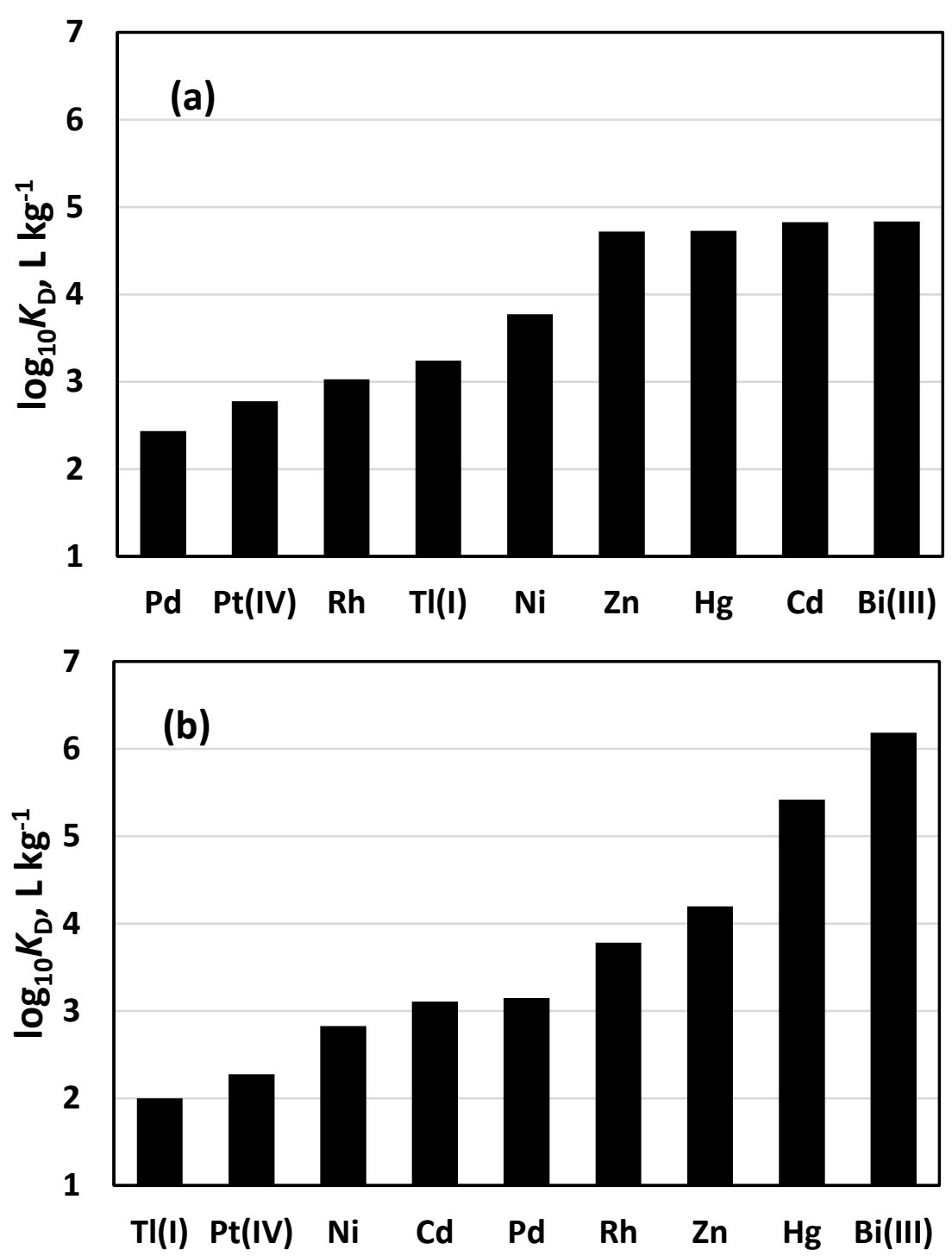